\title{
Operations Research for Green Logistics - An Overview of Aspects, Issues, Contributions and Challenges
}

\author{
Rommert Dekkera , Jacqueline Bloemhof ${ }^{b}$ and Ioannis Mallidis ${ }^{c}$ \\ a Erasmus School of Economics, Erasmus University Rotterdam, the Netherlands \\ ${ }^{b}$ Logistics, Decision and Information Sciences, Wageningen University, the Netherlands \\ cAristotle University of Thessalonki, Greece.
}

EI 2011-30

\begin{abstract}
The worldwide economic growth of the last century has given rise to a vast consumption of goods while globalization has led to large streams of goods all over the world. The production, transportation, storage and consumption of all these goods, however, have created large environmental problems. Today, global warming, created by large scale emissions of greenhouse gasses, is a top environmental concern. Governments, action groups and companies are asking for measures to counter this threat. Operations research has a long tradition in improving operations and especially in reducing costs. In this paper, we present a review that highlights the contribution of operations research to green logistics, which involves the integration of environmental aspects in logistics. We give a sketch of the present and possible developments, focussing on design, planning and control in a supply chain for transportation, inventory of products and facility decisions. While doing this, we also indicate several areas where environmental aspects could be included in OR models for logistics.
\end{abstract}

\section{Introduction}

Operations Research (OR) has been described as the science of better (the slogan of the INFORMS society) as it mainly focuses on minimizing the costs of existing processes.. Yet in today's society, it is not only profits that are important as many people, companies and governments are concerned about the sustainability of our society. So can Operations Research also contribute to a better environment? To our opinion, the role of OR for the environment should get more attention. Operations Research leads to a more efficient use of resources, which is not only cost attractive, but also tends to create less emissions of greenhouse gases. Secondly, Operations Research helps to identify the trade-offs between environmental aspects and costs. Very often, much reduction in 
emissions can be achieved with only a marginal increase in costs. Operations Research techniques and especially multi-criteria decision analysis is therefore an important method in this respect.

In this review, we will highlight its (possible) contributions to green logistics, which is the study of practices that aim to reduce the environmental externalities, mainly related to greenhouse gas emissions, noise and accidents, of logistics operations and therefore develop a sustainable balance between economic, environmental and social objectives (http://www.greenlogistics.org/, last accessed on August, 16, 2011). We deal with all aspects of logistics such as transportation, warehousing and inventories, and address the related environmental aspects such as emissions of greenhouse gases, noise and use of scarce resources. We will not differentiate between green logistics and green supply chain management. While we mainly focus on transportation, we take a broader (supply chain) perspective. However, we will not address environmentally conscious manufacturing or waste management. The purpose of this overview is to give a sketch of the present and possible developments. As many papers are presently being written, we do not claim to cover all. Instead we focus on the structure of the field and illustrate this with some representative papers, the choice of which always remains subjective. There are other overviews, such as Srivastava (2007) on green supply chain management and Shibi and Eglese (2010) on combinatorial optimization and green logistics, but ours is more comprehensive and more detailed with respect to transportation. In this sense, we fill the gap in industrial ecology as observed by Sheu, Chou et al. (2005) on the integration of logistics flows in a green supply chain. A recent book by McKinnon et al. (2010) has some overlap with this review, but we take a wider perspective. Finally, we would like to mention that our structuring is also in line with the business perspectives of consultants (see Palanivelu, and Dhawan, 2011).

In our review, we follow to a large extent the supply chain structure given by Chopra and Meindli (2010). First we discuss the main physical drivers behind a supply chain and examine transportation in section 2, products and inventories in section 3 and facilities in section 4 . We investigate the main choices in these drivers which affect environmental performance.

We consider these options in the three decision phases of a supply chain, namely design, planning and control, while we also discuss reverse supply chains. In section 5 , we discuss the design of a supply chain and how the combination of the drivers affects the environment. Section 6 examines the design of reverse and closed loop supply chains. Section 7 focuses on the three cross functional drivers, viz. sourcing, planning and pricing (revenue management) and in section 8 we take a closer look at the operational planning of supply chains. Green supply chain metrics are examined in section 
9 and section 10 describes the OR methods that helps in making the trade-offs in green logistics, viz. multi-criteria decision making. Figure 1 describes the proposed framework of this paper.

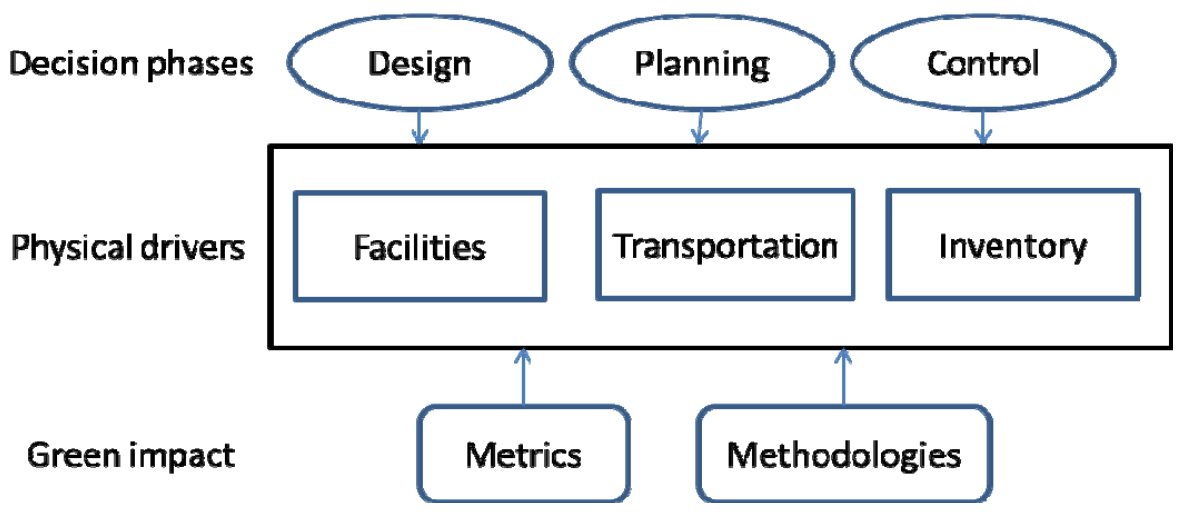

Figure 1: Framework of the paper

\section{Transportation}

With respect to the environment, transportation is the most visible aspect of supply chains. Transportation $\mathrm{CO}_{2}$ emissions amount to some $14 \%$ of total emissions, both at global and EU level (Stern 2006 and EEA 2011). Transportation is also a main source for $\mathrm{NO}_{x}, \mathrm{SO}_{2}$, and PM (particulate matter or fine dust) emissions. McKinnon and Woodburn (1996) and Piecyk and McKinnon (2010) have done studies of the most relevant factors for $\mathrm{CO}_{2}$ emissions in road transport. They developed a framework with five types of factors, viz. structural factors influencing modal split, commercial factors influencing load factors, operational factors, functional factors and finally external factors influencing carbon intensity of fuel. Since we also address other modes of transport in this paper, we will change their framework somewhat. We examine four choices with respect to transportation which are supported by operations research models, namely, mode choice (or modal split), use of intermodal transport, equipment choice and fuel choice. The commercial factors will be discussed in later sections.

\subsection{Mode choice}

One of the main choices in transport is the mode of transportation, viz. transport by plane, ship, truck, rail, barge or pipelines. Each mode has different characteristics in terms of costs, transit time, accessibility, and also different environmental performance. In reality, the choices are limited, as the transport mode is often determined by the type of product (e.g. liquid, bulk or package) and the distance to be travelled. In case of intercontinental supply chains, the main choice is between air and 
sea. For continental chains, it is mostly between truck, airplane, train or short sea ship. Time sensitive goods are often supplied by air, while large volumes of commodities (like coal, iron ore) are transported by rail, inland barge or pipeline (in case of gas or oils). Technological innovations such as cooled (reefer) containers and data loggers for temperature history have enabled a shift from air to slower modes, like truck or sea ship. There are few OR papers that deal with these issues. Leal Jr. et al. (2011) use the modal choice method to choose alternative ways of transporting bio-ethanol using financial and socio-environmental considerations. They find that the best choice is using roadway to feed long distance pipelines to delivering bio-ethanol directly to the port and report that long distance road transport is the worst of the alternatives considered.

Within transportation there is a large stream of papers identifying the shipper's preferences with respect to the different transportation characteristics, such as cost, quality, and speed. Although one has to be cautious with figures, because they depend heavily on the way they are calculated, we would like to present the following illustrative comparison of emissions between equipment types in several modes. The source is the Network for Transport and the Environment (see http://www.ntmcalc.se/index.html, last accessed on Feb 12, 2011). TEU is the standard measure for containers and one TEU is equivalent to a $20 \mathrm{ft}$. container and PM stands for Particulate Matters, also called fine dust.

\begin{tabular}{|c|c|c|c|c|c|c|}
\hline $\begin{array}{l}\text { Energy use / } \\
\text { Emissions } \\
\mathrm{g} / \mathrm{t} / \mathrm{km}\end{array}$ & $\begin{array}{l}\text { PS-type } \\
\text { container } \\
\text { vessel } \\
(11,000 \text { TEU) }\end{array}$ & $\begin{array}{l}\text { S-type } \\
\text { container } \\
\text { vessel } \\
(6,600 \mathrm{TEU})\end{array}$ & $\begin{array}{l}\text { Rail- } \\
\text { Electric }\end{array}$ & $\begin{array}{l}\text { Rail- } \\
\text { Diesel }\end{array}$ & $\begin{array}{l}\text { Heavy } \\
\text { Truck }\end{array}$ & $\begin{array}{l}\text { Boeing 747- } \\
400\end{array}$ \\
\hline $\mathrm{kWh} / \mathrm{t} / \mathrm{km}$ & 0.014 & 0.018 & 0.043 & 0.067 & 0.18 & 2.00 \\
\hline $\mathrm{CO}_{2}$ & 7.48 & 8.36 & 18 & 17 & 50 & 552 \\
\hline $\mathrm{SO}_{\mathrm{x}}$ & 0.19 & 0.21 & 0.44 & 0.35 & 0.31 & 5.69 \\
\hline $\mathrm{NO}_{\mathrm{x}}$ & 0.12 & 0.162 & 0.10 & 0.00005 & 0.00006 & 0.17 \\
\hline PM & 0.008 & 0.009 & $\mathrm{n} / \mathrm{a}$ & 0.008 & 0.005 & $n / a$ \\
\hline
\end{tabular}


We would like to highlight some important general relations which can be observed in this table. First of all, the bigger the transport unit in the same mode, the fewer the $\mathrm{CO}_{2}$ emissions per $\mathrm{g} / \mathrm{t} / \mathrm{km}$ (under fixed utilization loads). When comparing transport modes, we observe that water can easily carry heavy loads, hence water transport is $\mathrm{CO}_{2}$ efficient, that rail is more efficient than trucks, and a Boeing 747, though being a large plane, is not at all $\mathrm{CO}_{2}$ efficient when compared to the other modes. The modes do not differ much in $\mathrm{SO}_{x}$ emissions, except for the Boeing which clearly emits much more. Ships are responsible for high $\mathrm{NO}_{x}$ emissions whereas trucks and diesel rail are relatively clean compared to other modes. Finally the figures for fine dust (PM) do not differ much; here it depends very much on the particular engine type and whether soot filters are applied. It will be clear that not one mode is the preferred one from an environmental point of view and that OR methods are quite useful to identify the trade-offs between different mode choices. Below we sketch some recent contributions.

Bloemhof et al. (2011) use sustainability radar diagrams to investigate the environmental impacts of inland navigation compared to rail and road transport. Road transport is the largest contributor of emissions, although significant emission reductions have been achieved in recent years. If rail transport and inland navigation continue to refrain from innovations, the gap will close even further. It appears that only sustainable innovations that also contribute to profitability will succeed. The EU has set standards for $\mathrm{NO}_{\mathrm{x}}, \mathrm{SO}_{2}$ and $\mathrm{PM}$ emissions for trucks. As a result, trucks meeting the highest standard to date (Euro V) are much cleaner than most ships and trains. Ocean going ships emit huge amounts of $\mathrm{NO}_{x}$ (see Clean Air Initiative 2011). It is estimated that ship emissions will surpass total emissions generated by all land-based mobile, stationary and other sources by 2020 unless drastic measures are taken.

\subsection{Intermodal transport}

Closely related to the choice of transport mode is the use of a single transport load unit, like a container, over multiple transport modes, which is called intermodal transport. One of the main inefficiencies in transport is the handling of the goods at transshipment points. The introduction of containers has significantly reduced this inefficiency. Many goods shipped through intercontinental chains are shipped nowadays in containers. The land part of such a chain occurs by truck, rail or

inland barge. The rise of new (inland) container terminals to facilitate inland ship-rail-road combinations can save thousands of truck kilometers in congestion-sensitive areas and thus reduce the environmental impact. This also pertains for continental chains. The downside of intermodal transport is that it requires more coordination than single mode transport. Some papers can be found on the value of visibility in intermodal transport, yet few papers address environmental 
aspects. Goel (2010) presents a transportation model combining shipment and route choices to improve on-time delivery performance. These kinds of models could easily be adapted to include green metrics such as carbon emissions, energy used, spoilage and losses etc. Janic (2011) assesses environmental effects of transforming a large airport into a real multimodal transport node, connecting the airport to the high-speed rail transport network. Macharis and Bontekoning (2004) argue that intermodal freight transportation research is an emerging field that needs different types of models compared to those applied to unimodal transport.

\subsection{Equipment choice and efficiency}

Once a choice has been made about the transport mode(s), a decision must be made concerning the type and size of the transportation unit. This decision affects capacity, speed, economics and environmental performance. As said in section 2.1, the larger the transportation unit, the fewer $\mathrm{CO}_{2}$ emissions per $\mathrm{kg}$ transported, the fewer emissions of other gasses such as $\mathrm{NO}_{\mathrm{x}}, \mathrm{SO}_{2}$ and $\mathrm{PM}$, as shown in figure 1. Yet this relation only holds if the utilization or load factor remains and that is an important tactical / operational issue. New equipment is also more energy efficient. We can observe this in airplanes, where modern planes like the Airbus 380 or Boeing 777-300 are more energy efficient than the older Boeing 747-400, but also in ocean going container ships like the Emma Maersk, which can carry some 15,000 TEU, much more than the PS type in table 1 . However, the problem is that much capital is tied-up in equipment which lasts for decades, and that changes are therefore costly.

Papers on these subjects include D'Agosto and Ribeiro (2004) who focus on road fleet operation, taking into account minimizing fuel consumption as well as wider economic and environmental aspects. Venek and Morlok (2000) review efforts to improve the energy efficiency of the most frequently used trucks, and to shift more freight to energy efficient rail transportation. To this end, they identify the ratio of production to transportation energy use of major commodity groups in the U.S., through life cycle analysis and spatial analysis of freight patterns in the U.S. They claim that reductions in energy usage could be achieved by redesigning flow patterns and therefore advocate shifting more freight to energy efficient modes.

\subsection{Fuel choice and carbon intensity}

A fourth aspect in green transportation is the choice of fuel. Modern gasoline is cleaner compared to old gasoline. In the nineties and the first decade of the $21^{\text {st }}$ century, refineries focused on removing lead additives from gasoline, so that the air quality would be better. Biofuels based on corn or on organic waste can easily be mixed with standard gasoline. However, more extensive use requires 
adapting engines, which is quite expensive. To date, few OR papers are devoted to this aspect. However, OR models can play an important role in assessing the green performance of adapting biofuels. About $31 \%$ of all the US produced corn is fermented into ethanol to fuel cars. The total amount of fossil fuels used in the process to produce biofuel is not much less than the total amount of biofuel produced. Bai et al. (2011) focus on minimizing costs for refinery investment, feed stock, product transportation and public travel and uses a Lagrangiaan relaxation based heuristic algorithm to find feasible solutions. This work could easily be extended by also minimizing the use of fossil fuels.

Electric vehicles are environmentally friendly since their engines have almost no emissions and emissions in electric power stations can be controlled. However, they have a limited range, so for goods transport they require a change in operation with possible intermediate goods transshipment. Hence they are popular for city transport in combination with a transfer station in or just outside the city. This application can be cheaper than truck transport. To compensate for the short range a dense power re-supply network has to be set-up, possibly in conjunction with a swap of batteries. Finally, fuel choices are also important for ships, as coastal states may impose restrictions on fuel types. Visiting ports to bunker fuel cheaply may become an incentive in shipping route design.

\section{Products and inventories: life cycle}

A supply chain is also characterized by the products it supplies. Chopra and Meindl (2010) consider only the inventory aspects of products, but we take a more comprehensive view. The point is that some products are friendlier to the environment than others. Three product aspects are relevant in this respect. First, the way they have been produced (their carbon footprint), secondly, the way they have been transported and waiting for use (inventories) and thirdly, whether their value can be recovered after their use (reverse logistics). Finally, we also consider packaging and returnable transport items. The overall idea is that environmental aspects can be taken into account when choosing between different versions of the same product, even at the level of the individual customer. Moreover, that by measuring and publishing the environmental performance of a product, manufacturers are more likely to make "greener" products.

The first aspect, life cycle impact, is important since it indicates the resources needed to make the product. This can be energy, but also other scarce resources such as water. Some companies like Tesco, Walmart and Carrefour have started to indicate the carbon footprint (that is the total amount of carbon dioxide emitted for production and transport) of (some of) their products. The effect is that consumers can base their product selection based on this carbon footprint. The labeling seems easier 
than it is. The whole chain which leads to the product has to be investigated and allocation problems have to be tackled: if multiple products are made together in one process, which carbon emissions have to be allocated to which product? (see Quariguasi et al. 2010).

The storage of products also has an environmental impact although this is less visible than the transportation of products. Inventory holding costs play a large part in supply chain design, and the more storage is centralized, the less the storage costs. The environmental storage footprint consists of cooled/refrigerated storage for food or heated storage (in case of some oils) and evaporation during storage. A clear example of the choices to be made is the supply of tomatoes in the Netherlands in winter. They may be sourced from a warm country far away, but in that case much transportation is needed. On the other hand, they may also be produced nationally in greenhouses but in that case energy is needed for heating. Hence it will be clear that complex calculations need to be performed to make out which option is the best from an environmental point of view.

In the product lifecycle, the use of the product next to its fabrication should also be considered. Comprehensive results over all phases on the environmental impact of products are however, scarce. In order to improve the overall carbon footprint of a product, it is necessary to assign the footprint to material used, energy used, production, use and transportation (Quariguasi et al. 2010). For many product categories, there are also indicators for the energy use of products, e.g. in case of refrigerators, cars etc, under standardized conditions. Yet this is only one aspect in the whole picture.

When the use of a product has ended, the remaining value can be recovered, instead of land filling or incinerating the remains for energy recovery. In this way, some of the carbon footprint invested in the product can be reused. The recovery typically involves reverse logistics and this will be discussed in detail in section 6 . We like to note that this aspect also complicates lifecycle assessments.

Finally, we would like to mention packaging and returnable transport items, like pallets, containers and roll-cages. According to some reports (Palanivelu,and Dhawan, 2011) packaging represents some $23 \%$ of all waste weight. As all packages have to be transported to the retailer as well as to the waste processor, it is clear that reducing packaging saves the environment. An alternative to single-use packaging is returnable packaging, such as refillable bottles, beer kegs etc. Yet these create logistic problems as they have to be transported back to the place of origin and have to be cleaned. A major issue of all these re-usable items is that they are used in networks and their inventories need to be redistributed. This has been a topic of several OR models; see for example Gonzalez-Torre and Adenso-Diaz (2004).

\section{Facilities (warehouses, ports and terminals)}


Facilities are the third driver in supply chains. We will take a somewhat more comprehensive view than Chopra and Meindl (2010) and include transportation facilities as well. So next to distribution centers, we consider airports, railway stations and ports with container terminals. In recent years, the terms green facility and green buildings have gained much popularity. Several environmental aspects are important, viz. a) Internal transport and emissions

b) energy use of facilities

c) emissions of transport units used for transport to or from facilities

d) congestion around facilities

Most distribution centers operate electric equipment (like fork lift trucks) because there are no direct emissions involved (Mackinnon et al. 2010) and distances are short. Yet in container terminals where distances are long and the equipment has to cope with environmentally difficult conditions (short trips, many starts, etc) diesel-fuelled equipment is mostly used. Internal transport is therefore also an important driver for emissions and it is good for the environment if these can be reduced. An example of a study of transport distances in a container terminal and related emissions is given in Geerlings and Van Duin (2011). They favor compact facilities to reduce internal transport. There has also been much pressure from port authorities to reduce emissions. For example, the Rotterdam Port Authorities contractually oblige a substantial reduction in emissions when new container terminals are built and operated. Also manufacturers of container handling equipment are now propagating electrically operated equipment. Operations Research methods for warehouses traditionally focus on the reduction of travel times, although primarily to improve efficiency. However, since they reduce the amount of travelling, they are also beneficial for the environment; see for example De Koster et al. (2007) and Dukic et al. (2010).

The energy use of facilities has been a concern for many companies and not only for cost reasons. Several zero emission warehouses have been built, for example, by installing energy saving installations, using sophisticated lighting systems and solar cells; see, for example, Palanivelu and Dhawan (2011). Yet, hardly any OR models have been developed for these purposes.

Thirdly, there are emissions of transport units in or near facilities. Typically ships leave their engines on while moored. This generates substantial emissions also because the engines are running in less efficient modes. Ports need to introduce requirements to use electricity supplied from onshore installations (wall current or cold-ironing).

Finally, facilities are the nodal points in transportation networks and hence often a bottleneck. The use of wave systems in the arrival and departure of planes even aggravates this (in a wave system arrivals and departures are clustered in time). Such systems are applied to provide short connection 
times for transshipping goods or passengers. Yet it creates peaks in arrivals and if there are any disturbances, long waiting may be the result. In general, waiting has negative environmental consequences. Airplanes which have to wait before landing fly in waiting routes. Ships that have to wait offshore can anchor and emit much less. Trucks waiting for container terminals may also keep their engines on. Engines running in these idle modes typically have much higher emissions than normal. Several OR methods, such as queuing theory and simulation are applied to study these phenomena, although often with an economic incentive as waiting is also inefficient. The issue however is that these real systems have quite a fluctuating demand and short periods of overflow, aspects which are typically left out of queuing models. Next, there are more and more appointment systems where arrivals are to some extent controlled in order to avoid congestion and hence emissions; see Dekker et al. (2010), yet few papers exists on queuing models with appointments.

\section{Supply and transport chain design}

In this section we show how the drivers specified in the previous sections, viz. transportation and facilities can be combined in a supply or transport chain, ensuring that customer requirements are fulfilled. We will consider how the choices of each driver should be made and therefore address the following aspects:

-sourcing: where do we get products from (which country)

-determination of production and distribution concepts

-determination of the type, number and location of facilities

-choice of the transportation means

-choice of the transportation speed

-choice of the transportation concept

\subsection{Sourcing}

The sourcing of products directly determines the need for transportation. The provision of many cheap products from Asia has created huge transportation streams to Europe and the US. Nearby alternatives, like Mexico for the US and Turkey for the EU could also be used. Differences in wages are the main drivers for the difference in product costs, but many other factors also play a role. The choice between the so-called far shoring and near shoring also involves other issues, as shorter transportation times also increase flexibility. lakovou et al. (2010) propose an analytical model that includes closed formed solutions to investigate the cost and environmental effect of near shoring a portion of production processes next to the serving markets. 


\subsection{Production concepts}

Production concepts indicate how production is organized. A well-known concept is the just-in-time (JIT) concept, which states that inventories should be minimized and that shipments should only cover short-term needs. This reduces inefficiencies in organizations, yet it also implies many small rush transports, with few options to find return trips (because of the small amount of time available for planning). This is not a big issue if the suppliers are close to the manufacturer, as then only small distances need to be travelled. However, this is not always the case and JIT principles have also been applied in cases where suppliers are more than $100 \mathrm{~km}$ away.

The way products are assembled and transported also has environmental aspects. For example, we can choose to import finished cars or choose to transport car parts and modules and assemble these locally. Repackaging is another option. For example, wine or beer can be transported in large quantities and bottled locally. This way of assembling a product reduces transportation.

Other examples are diapers from which the air is sucked away so that more fit in a package.

Finally, there are OR models that optimize the loading of containers and other bins. Load and bin planning also improve transport efficiency. Several OR models have been published in this respect, but we are not aware of scientific papers addressing the environmental consequences.

\subsection{Facility location}

Within OR there is a whole stream of research on facility location, which mainly deals with the number and location of distribution centers (DCs). As inbound flows to DCs tend to be consolidated in full trucks and outbound flows tend to be in smaller units, the number of DCs has a large effect on transport efficiency. Environmental aspects of supply chain design and facility location in particular have recently received considerable attention. We would like to mention the following papers. Li et al. (2008) propose a bi-objective (profit maximization and emissions minimization objective) mathematical programming methodology to optimize distribution center locations taking into consideration transportation costs and transportation/production carbon emissions. Mallidis et al. (2010) propose a multi-objective mixed integer programming model (MIP) to examine how distribution center locations (DCs), leasing or outsourcing transportation and warehouse operations decisions, affect the system's environmental performance in terms of (inbound and outbound) transportation $\mathrm{CO}_{2}$ and PM emissions. Wang et al. (2011) suggest a multi-objective optimization model for supply chain network design. They consider transportation, handling and next investment 
costs on green equipment or technology. Next they examine the $\mathrm{CO}_{2}$ emissions generated by production and distribution facilities.

Diabat and Simchi-Levi (2010) also consider a MIP model for the design of a supply chain with a cap on the amount of $\mathrm{CO}_{2}$ produced. $\mathrm{CO}_{2}$ emissions come from warehouses, plants and transports to customers. They show that supply chain costs increase if the cap becomes tighter. Ramudhin et al. (2010) are among the first to propose a carbon market sensitive strategic planning model for sustainable supply chain network design. They show that considerations of internal and external control mechanisms are of great importance to decision makers when designing sustainable supply chains. Chaabane et al. (2010) extend this approach and introduce a mixed-integer linear programming based framework for sustainable supply chain design that considers life cycle assessment (LCA) principles in addition to the traditional material balance constraints at each node in the supply chain. They apply it to the aluminum industry and conclude that the present emission trading scheme must be strengthened.

Harris et al. (2011) consider both logistics costs and $\mathrm{CO}_{2}$ emissions in supply chain optimization. They take into account the supply chain structure (number of depots) and different freight vehicle utilization ratios (90\%, $75 \%$ and $60 \%$ ). They illustrate their approach with a simulation model of the European automotive industry.

\subsection{Transportation: means and route}

Once the sourcing decision has been made, the mode and means of transport must be chosen. In this there is also a trade-off between inventories and transportation. There are several options with respect to transport: e.g. direct versus indirect routes and the choice of the port of entry into a continent. Typically studies have been done with costs as optimization criterion, but some recent studies also include environmental aspects. For example, Mallidis et al. (2010) include a choice of port of entry in their supply chain design model. As transport by ship is environmentally friendly, it pays off to choose the nearest port for a customer.

\subsection{Transport speed}

During the 2008/2009 economic crisis, there was an oversupply of container ships and one of the simplest actions was to slow down the speed of the ships from 26 to 21 knots per hour, which resulted in a different schedule but also in considerable savings in fuel costs and hence also in emissions. This was called slow steaming. Later also super slow steaming was introduced where ships would sail only 18 knots per hour. Several studies analyze the effect of the choice of speed; see for 
example Carriou (2011) and Psaraftis et al. (2009). They also consider the effect of the need for more equipment as well as the effect of longer transit time on cargo. Operational speed optimization is applied in planes and is upcoming for large ships. It concerns changing the speed to be on time in case of varying conditions like weather. Sophisticated software looks for wind directions and speeds and selects those routes with the most tail wind. It adapts the speed to the desired arrival time, thus avoiding overuse of fuel; see for example Fagerholt et al. (2009) for an application in tramp shipping.

\subsection{Transportation concepts}

An important transportation concept is consolidation, especially in the Less-Than-Truckload (LTL) sector. In this case, small shipments are combined with larger ones to achieve efficiencies of scale for transport over long distances. The disadvantage of such transport is that time is needed to consolidate the cargoes, which means that it is more difficult to plan them just-in-time.

Apart from equipment choice there are also strategic choices of delivery time. This is reflected in the various services offered by express carriers, such as FedEx, TNT and UPS (see for example TNT 2011). They provide several options for transporting small and valuable items, such as same day, next day and deferred delivery. The fastest choice is accomplished by having faster transport (e.g. air instead of road) and reducing consolidation options (i.e. waiting for other cargo). In fact, the fastest transport is a single courier accompanying a unique transport, but it is also the most costly and hence it is likely to generate many emissions.

Express carriers also specialize in reliable transport times. The guaranteed delivery times can only be achieved by running scheduled services according to a fixed timetable. Large variations in the demand now imply that load factors and utilizations are typically low, which is especially visible in express airlines. It is also clear in the difference between parcel transporting companies and the large express companies, like UPS and FedEx. The former is much more efficient and cheaper in transporting their goods by waiting longer for other cargo. Within the express business, there is a difference between B2B deliveries and B2C deliveries. The latter is to individual customers, which is inherently more difficult as customers may not be at home and the address may be more difficult to find. Kull, Boyer et al. (2007) focus on this last-mile supply chain - the portion of the supply chain delivering products directly to the customer. Consolidation concepts for this last-mile transport are, for example, delivering packages in city centers (postal offices, retail shops), where customers can pick up their package using a unique pincode. This avoids multiple delivery attempts because people are not at home. 
A third concept worth mentioning is the use of direct trips versus so-called milk runs in which a number of customers are served in one route. Milk runs are typically more efficient in case of small shipments to customers located not far from each other. Shipments can be combined and larger and therefore more efficient transport units can be used. This also creates some inefficiency as cargo typically travels longer before reaching its destination. This aspect is quite visible in airline networks. Some use triangular routes on long distances, whereas others go for direct routes only. Often only direct routes are used for short flights.

Next, we would like to mention the choice between direct and indirect transport or also called direct versus hub-and-spoke transportation. The latter consolidates transport to hubs in larger amounts and hence in more efficient transport units, whereas direct transport uses small transport units to provide faster service. Planning direct transports is easier than indirect transport as in the latter the schedules need to be coordinated to provide seamless connections. Transfer of goods from one mode to another is often a delicate business, as errors and disturbances typically occur or become visible at the transfer point. The handling of most not containerized cargo is quite labor intensive, with the result that transfer is relatively costly. Yet we see intermediate transport concepts coming back in city logistics where they have several advantages. First of all, cities require different transport means (smaller and less polluting, e.g. electric) than highways do, as large trucks are more $\mathrm{CO}_{2}$ and cost efficient. Accordingly in several city concepts, intermediate transfer points are used to transfer goods from large trucks to environmentally friendly small city trucks or even canal boats. Furthermore, consolidation efficiency gains can also be achieved by combining transports from different suppliers to neighboring shops.

A final important recent logistic concept is the use of cross-chain control towers, whereby different

supply chains are combined in order to make efficiency gains. For example, sharing transport equipment has a positive environmental impact, because less equipment is needed. Although all these concepts are related to the environment and have definite OR aspects, papers incorporating both are lacking.

\section{Product recovery and closed loop supply chains}

Many products are not completely consumed when their use is stopped and almost all have some remaining value. Reverse logistics consists of all logistic activities necessary to unlock this value through product recovery. It consists of collecting discarded goods, inspecting and sorting them, followed by some recovery action, which can either be a simple cleaning or a complex disassembly, and finally a remanufacturing process and a remarketing of the output. Which recovery action (direct 
re-use, remanufacturing, parts retrieval or recycling) is taken depends on the state of the product, the associated costs and the demand for the results. When reverse logistics forms an integrated part of a supply chain, we use the term a closed loop supply chain.

Many papers have been written on reverse logistics, because managing returns is complicated by several problems. For example, collection networks need to be set-up and recovery operations need to be planned. The environmental effect of reverse logistics consists of offering products or parts made or retrieved from discarded products and recycled materials instead of having to make new ones. However, it may be difficult to guarantee the quality of recovered goods, and the cleaning processes may be polluting. Moreover, much transportation may be needed to generate large enough volumes for recycling or remanufacturing processes. Yet, in general reverse logistics and closed loop supply chains are considered to be environmentally friendly (Geyer and Jackson 2004). Many surveys have focused on closed-loop supply chains (Linton, Klassen et al. 2007; Srivastava 2007). However, the papers mentioned in these surveys do not explicitly deal with environmental impacts in a supply chain context, but instead, for example, use units returned as a measure for environmental impact. Quariguasi et al. (2010) discuss if and for which cases the assumption of a sustainable closed-loop supply chain holds.

Barker and Zabinsky (2010) propose a multi-criteria decision making model using the analytical hierarchy process for designing reverse logistics networks, while Alshamrani et al. (2007) propose a heuristic procedure for developing pick-up along with delivery root design strategies for returning materials. Moreover, product recovery issues are also tackled. Finally we would like to mention Le Blanc, Van Krieken et al. (2008) who describe the possibilities to improve vehicle routing for reverse logistics.

\section{Supply chain planning and control}

On the tactical side, with time horizons of a quarter to a year, several key decisions have to be made, such as forecasting, production capacity planning, inventory control and marketing operations, including pricing strategies. Here we focus on the environmental aspects due to pricing, supply chain planning and procurement.

\subsection{Pricing and emission trading}

One of the most successful Operations Research applications from the last decade is revenue management. While it was originally developed for airlines, it is now also used for hotels and high speed railways, etc. Basically, it aims to get most out of scarce capacity, in the sense that prices are 
varied according to capacity left under varying demand. Compared to a time invariant price, it allows lower prices at an early stage compensated by a high price later. Furthermore, customers have a monetary incentive to switch to moments where more capacity is available and hence prices are lower. The effect has been that capacity is much better used. For example, airlines nowadays operate with much higher load factors than in the seventies. A study by Agatz et al. (2008) is one of the few examples where revenue management for package delivery is applied to decrease total kilometers driven. They demonstrate what e-tailers can learn from the airline pricing, by stimulating customers to choose delivery windows in which neighboring customers have already placed delivery orders. Next to revenue management, which is, in fact, a tactical and operational instrument, we would like to mention the carbon emissions trading scheme which was one of the main results of the Kyoto Protocol. This scheme has been institutionalized in the European Union Emission Trading System (EUETS) in 25 of the EU member countries and similar schemes have been adopted in other countries as well. In such a scheme, companies are given an initial allowance for carbon emissions, which is reduced in time. Companies wanting to emit more, have to buy emission rights on the market. There have been several problems with the system. When a recession came in and it appeared that some countries had been given very large allowances, carbon prices dropped to almost zero in 2007. As the global economy is recovering, carbon prices have gone up again. One of the main issues is which industries are to be included in the scheme and how many rights are to be allocated freely. To date, only the large industries are included, as administration efforts would otherwise be prohibitive.

Several researchers have investigated how companies should react to such a carbon cap. We would like to mention two papers. Benjaafar et al. (2010) investigate these for very simple inventory control models. Their work has been extended by Hua et al. (2009).

\subsection{Supply chain planning}

Supply chain planning consists of making capacity plans over medium time horizons. In this phase transportation, warehouse capacity, inventories etc are planned. Several decision support systems using OR models exist and these are often referred to as Advanced Planning Systems. They all seem to focus on the traditional cost objective. Good planning, however, also reduces the need for corrective actions, such as emergency shipments. These generally have a negative environmental performance since these types of transport are quite inefficient: small volumes with fast transport modes. So indirectly OR also contributes to a better environment, although this aspect has not been quantified.

\subsection{Procurement}


A major element in stimulating green behavior is the inclusion of environmental aspects in the procurement or tendering process. In this way, green behavior pays off for companies. However, it also makes these processes more complex and in fact multi-criteria decision approaches are needed. Ates, Bloemhof et al. (2011) study the impact of external environmental investments, i.e. investments in collaboration activities with suppliers, related to production and logistics. Such investments may take the form of joint problem-solving sessions, information sharing or establishing common goals etc. (Vachon and Klassen, 2006). As the environmental performance of suppliers has a direct impact on the products of the purchasing firm, it is crucial to assure the same level of environmental awareness.

\section{Operational control of supply and transport chains}

Although it may seem that the strategic choices determine most of the environmental impact, also in the daily operations there is much scope for environmental improvement, especially with $O R$ methods. We would like to mention choices such as equipment allocation, route navigation, and vehicle routing. We would like to note that equipment pooling and speed optimization can be done both at a tactical as well as an operational level. Beltran et al. (2009) give an example of methods for the allocation of green vehicles to routes. Route navigation indicates the route between two given points. Navigation software for cars, trucks and planes apply sophisticated shortest-path algorithms and reduce the amount of kilometers to be travelled. Accordingly, they also reduce environmental emissions. A vehicle routing (VRP) package, applying OR methods also reduces the number of kilometers driven. The Dutch transport economics agency NEA (now part of Ecorys) reported that VRP packages typically reduce the cost by some $3 \%$ to $5 \%$ because fewer kilometers need to be driven and load factors are higher (NEA 1997). Palmer's dissertation presents an integrated routing and emissions model in which speed can be varied. One of his results is that savings up to $5 \%$ in $\mathrm{CO} 2$ emissions can be obtained. His work was extended by Maden et al. (2010) who also did a case study with delivery vehicles in the UK. Also Ubeda et al. (2011) present a case study. A further step was made by Bektaş and Laporte (2011) who in their Pollution-Routing Problem use a comprehensive emission model taking load and speed into account in vehicle routing and their effect on emissions.

Finally, we would like to mention equipment pooling. Pan et al. (2011) describe a case where transportation equipment is pooled between several companies in order to increase load factors (which are said to be only $70 \%$ ). They quantify the effect of this pooling on $\mathrm{CO}_{2}$ emissions.

\section{Metrics}


An important element in the use of optimization for the environment is the use of metrics. Through metrics the environmental effect is made clear and different alternatives can be compared. Aronsson and Huge-Brodin (2006) identified the measurement of emissions as one of the most important ways to estimate environmental impact. Moreover, metrics can also be used in the transfer of goods and services in a supply chain as they indicate the environmental effect of each supply chain party. An important example of such a metric is a $\mathrm{CO}_{2}$ calculator which determines the amount of emissions for all transports a company has made. Several are available today, both for individual customers and companies. They are based on simple formulas and average statistics. An attempt to set a worldwide standard to make the calculations comparable among companies is SCGreen (2011). They take the total number of kilometers driven, average load factors, average type of equipment, average fuel use and derive the total estimated emissions (Boer et al., 2008).

Yet, several issues are important in calculating transport emissions in the aforementioned ways. First of all, to what extent are return trips or backhauls taken into account? Secondly, if multiple cargos are transported in one trip, how should the emissions be allocated to them? They could be allocated based on volume or weight, but this is not likely to give the same answer, so a subjective element is involved.

Hervani et al. (2005) identifies a selected list of other metrics that range from atmospheric emissions to energy recovery. They examine measures for on- and off-site energy recovery, recycling and treatment, spill and leak prevention and pollution prevention. Several authors use CED (Cumulative Energy Demand) as a measure of environmental impact. De Haes (2006) observes a high correlation between CED and most of the environmental impact categories used for life cycle analysis. Sundarakani et al. (2010) also present a methodology to model carbon footprints across the supply chain. They use both long-range Lagrangian and Eulerian transport methods. Finally we like to mention Mierlo et al. (2004) who introduce two rating systems assessing the environmental damage caused by vehicles. They assess electric, hybrid and fuel cell vehicles using a simplified life cycle analysis (LCA) method.

\section{Specific OR methods: Multi-criteria decision making}

Most applications of OR tools focus on efficiency of operations. This translates directly into fewer activities (transports, etc) and hence also in fewer emissions. Yet, it is not always that easy and tradeoffs have to be made, e.g. in procurement. Multi-criteria decision making (MCDM) methods can typically help in such situations. Some researchers apply multi-objective optimization. For example, Mallidis et al. (2010) presents supply chain designs made under several objectives, viz. $\mathrm{CO}_{2}$ and cost 
minimization. The supply chain designs do not differ much. Furthermore, MCDM methods can help to identify the synergies between cost and environmental objectives. Yet few applications of MCDM have been reported in this respect. We would like to mention Macharis et al. (2010) on the strategic choices for the Flemish transportation and logistics sector and Sasikumar (2010) and Barker et al. (2010) on strategic issues for reverse logistics. We have already mentioned the study by Wang et al. (2011) on supply chain design. Furthermore, there is a study by Azapagic and Clift (1999) who discuss multi-objective optimization in Life Cycle Assessment (LCA). They state that the value of multiobjective optimization in system analysis lies in providing a set of alternative options for system improvements rather than a single prescriptive solution, thus enabling the choice of the Best Practicable Environmental Option (BPEO) and Best Available Technique Not Entailing Excessive Cost (BATNEEC).

One of the most important questions in green logistics is how to identify preferred solutions balancing environmental and business concerns (Quariguasi et al. 2009). Improving environmental quality comes at a cost, so the question is which trade-offs occur between the environmental impacts of an economic activity and its costs, and what are best solutions balancing ecological and economic concerns? The aim is to determine solutions in which environmental damage can only be decreased if costs are increased. These solutions are called eco-efficient. The idea of exploring best alternatives is based on Pareto-optimality (Huppes and Ishikawa, 2005). Despite the extensive literature on multi-objective programming, determining eco-efficient frontiers using multi-objective mixed integer programming models is quite new.

\section{Conclusions}

Operations research is most often associated with cost minimization. Yet there is a substantial impact on the environment, although this is often not recognized. Environmental advocates typically plead for a technology change, e.g. going from oil-based fuel to electric cars. However in all systems, the way they are operated is an important determinant in the environmental performance. For example, container ships lowering their speed from 26 to 18 knots reduce their fuel use by $30 \%$. Accordingly, OR has and will bring important contributions to the environment, but it is quite often implicit, a fact which has become evident from this review. It would be better if OR emphasized its value for the environment. New models will be required to address the multitude of decisions needed to improve the

environment. 


\section{Acknowledgement}

The authors are grateful to Remy Spliet and the referee for useful comments.

\section{References}

Agatz, N.A.H., Campbell, A., Fleischmann, M. \& Savelsbergh, M.W.P. (2008). Challenges and Opportunities in Attended Home Delivery. In B. Golden, R. Raghavan \& E. Wasil (Eds.), The Vehicle Routing Problem: Latest Advances and New Challenges (pp. 370-396).

Aronsson, H., \& Huge-Brodin, M. (2006). The environmental impact of changing logistics structure. The International Journal of Logistics Management, 17, 394-415.

Ates, M. A., Bloemhof, J., Van Raaij, E. \& Wynstra, F. (2011). Proactive environmental strategy in a supply chain context; the mediating role of investments. International Journal of Production Research. "in Press".

Azapagic, A., \& Clift, R. (1999). Life Cycle Assessment and multiobjective optimisation. Journal of Cleaner Production, 7, 135-143.

Azzone, G., \& Noci, G. (1996). Defining environmental performance indicators: an integrated framework. Business Strategy and the Environment, 5, 69-80.

Bauer, J., Bektas, T., \& Crainic, T.G. (2010). Minimizing greenhouse gas emissions in intermodal freight transport: an application to rail service design. Journal of the Operational Research Society, 61, 530-542. doi: org/CORMSIS-09-01.

Bektas T. and Laporte G. (2011). The Pollution-Routing Problem. Transportation Research B "in press".

Beltran, B., Carresea, S., Cipriani, E., \& Petrellia, M. (2009). Transit network design with allocation of green vehicles: A genetic algorithm approach, Transportation Research Part C: Emerging Technologies, 17, 475-483.

Benjaafar S., Li Y., Daskin M., 2010. Carbon footprint and the management of supply chains: Insights from simple models. <http://www.ie.umn.edu/faculty/faculty/pdf/beyada-3-31-10.pdf>[accessed May 24, 2010].

Blauwens, G., Vandaele, N., Van de Voorde, E., Vernimmen, B., \& Witlox, F. (2006). Towards a Modal Shift in Freight Transport? A Business Logistics Analysis of Some Policy Measures. Transport Reviews, $26,239-251$. 
Bloemhof, J., Van der Laan, E.A., \& Beijer, C. (2011). Sustainable Inland Transportation. International Journal of Business Insights and Transformation, 3(3), 26-33.

Cariou, P. (2011). Is slow steaming a sustainable means of reducing $\mathrm{CO}_{2}$ emissions from container shipping? Transportation Research Part D, 16, 260-264.

Chaabane, A., Ramudhin, A., \& Paquet, M. (2010). Design of sustainable supply chains under the emission trading scheme. International Journal of Production Economics, "in Press".

Chopra, S. \& Meindl, P. (2010). Supply Chain Management, Strategy, Planning and Operation, Pearson, Upper Saddle River, NJ, (Chapter, 3).

Corbett, C.J., \& Kleindorfer, P.R. (2001a). Environmental management and operations management: introduction to part 1 (manufacturing and eco-logistics). Production and Operations Management, $10,107-111$.

Corbett, C.J., \& Kleindorfer, P.R. (2001b). Environmental management and operations management: introduction to part 2 (integrating operations and environmental management systems). Production and Operations Management, 10, 225-227.

Corbett, J.J., Wang, H., \& Winebrake, J.J. (2009). The effectiveness and costs of speed reductions on emissions from international shipping. Transportation Research Part D, 14, 593-598.

D'Agosto, M., \& Ribeiro, S. K., (2004). Eco-efficiency management program - a model for road fleet operation. Transportation Research Part D, 9, 497-511.

Dekker, R., Van der Heide, S., \& Van Asperen, E.A. (2010). A chassis exchange terminal to reduce truck congestion at container terminals, Paper 111, Proceedings LOGMS Conference, Busan, Korea,

De Koster, R., Le-Duc, T., and Roodbergen,K.J. (2007). Design and control of warehouse orderpicking: A literature review, European Journal of Operational Research, 182, 481-501.

Diabat, A., \& Simchi-Levi, D. (2009). A carbon-capped supply chain network problem. Proceedings ofthe IEEE International Conference of on Industrial Engineering and Engineering Management, USA, 532-527. doi:org/10.1109/IEEM.2009.5373289.

Đukic, G., Česnik, V., \& Opetuk, T. (2010). Order-picking Methods and Technologies for Greener Warehousing, Strojarstvo, 52, 23-31.

Fagerholt, K., Laporte, G., \& Norstad, L., (2010). Reducing fuel emissions by optimizing speed on shipping routes. Journal of the Operational Research Society, 61, 523-529. 
Geerlings, H., \& Van Duin, R. (2011). A new method for assessing CO2-emissions from container terminals: a promising approach applied in Rotterdam. Journal of Cleaner Production, 19, 657-666.

Geyer, R., \& Jackson, T., (2004). Supply loops and their constraints: The industrial ecology of recycling and reuse. California Management Review, 46, 55-73.

Goel, A. (2010). The value of in-transit visibility for supply chains with multiple modes of transport. International Journal of Logistics: Research and Applications, 13, 475-492.

Gonzalez-Torre, P. L., \& Adenso-Diaz, B. (2004). Environmental and reverse logistics policies in European bottling and packaging firms. International Journal of Production Economics, 88, 95-104.

Harris, I., Naim, M., Palmer, A., Potter, A., \& Mumford C. (2010). Assessing the impact of cost optimization based on infrastructure modelling on $\mathrm{CO} 2$ emissions. International Journal of Production Economics, "in Press".

Hoens, K.M.R. Tan, T., Fransoo, J.C., \& van Houtum, G.J. (2010). Effect of carbon emission regulations on transport mode selection in supply chains. Retrieved from the Eindhoven University of Technology website: http://alexandria.tue.nl/repository/books/672727.pdf.

Hua, Guowei, Cheng, T.C.E. and Wang, Shouyang, Managing Carbon Footprints in Inventory Control (November 24, 2009). Available at SSRN: http://ssrn.com/abstract=1628953

Huijbregts, M. A., \& Rombout, L. J. A. (2006). Is Cumulative Fossil Energy Demand a useful indicator for the environmental performance of products. Envrionmental Science and Technology, 40, 641-648.

Huppes, G., \& Ishikawa, M., (2005). A framework for quantified eco-efficiency analysis. Journal of Industrial Ecology, 9 (4), 25-41.

Janic, M. (2011). Assessing some social and environmental effects of transforming an airport into a real multimodal transport node. Transportation Research Part D, 16, 137-149.

Kleindorfer, P.R., Singhal, K., \& Van Wassenhove, L.N. (2005). Sustainable Operations Management. Production and Operations Management, 14, 482-492.

Kull, T. J., \& Boyer, K. (2007). Last-mile supply chain efficiency: an analysis of learning curves in online ordering. International Journal of Operations \& Production Management, 27, 409.

Le Blanc, L., Van Krieken, M., Krikke, H., \& Fleuren, H. (2006). Vehicle routing concepts in the closed loop container network of ARN - a case study. OR Spectrum, 28, 53-71. 
Leal Jr, I.C., \& D'Agosto, M.de-A. (2011). Modal choice evaluation of transport alternatives for exporting bio-ethanol from Brazil. Transportation Research Part D, 16, 201-207.

Li, F., Liu, T., Zhang, H., Cao, R., Ding, W., \& Fasano, J.P., (2008). Distribution Center Location for Green Supply Chain. Proceedings of the IEEE International Conference on Service Operations and Logistics, and informatics, Beijing, 2951-2956. doi: org/10.1109/SOLI.2008.4683040.

Linton, J. D., \& Klassen, R., (2007). Sustainable supply chains: An introduction. Journal of Operations Management, 25, 1075-1082.

Macharis, C., De Witte, A., \& Turcksin, L. (2010). The Multi-Actor Multi-Criteria Analysis (MAMCA) application in the Flemish long-term decision making process on mobility and logistics. Transport Policy, 17, 303-311

Macharis, C., \& Bontekoning, Y. M., (2004). Opportunities for OR in intermodal freight transport research: a review. European Journal of Operational Research, 153, 400-416.

Maden W., Eglese R. and Black D. (2010) Vehicle routing and scheduling with time-varying data: A case study. Journal of the Operational Research Society, Vol. 61(3), 515-522.

Mallidis, I., Dekker, R., \& Vlachos, D. (2010). Greening Supply Chains: Impact on costs and design. Retrieved from Erasmus University, Econometric Institute website: http://repub.eur.nl/res/pub/20375/.

McKinnon, A.C., \& Woodburn, A., (1996). Logistical restructuring and road freight traffic growth: an empirical assessment. Transportation, 23, 141-161.

McKinnon, A., Cullinane, S., Browne, M., Whiteing, A., (2010). Green Logistics: Improving the environmental sustainability of logistics. London: Kogan, (Chapter 8$)$.

Mierlo, J.V., Timmermans, J.M., Maggeto, G., van den Bossche, P., Mayer, S., Hecq, W., Govaerts, L., Verlaak, J. (2004). Environmental rating of vehicles with different alternative fuels and drive trains: a comparison of two approaches Transportation Research Part D, 9, 387-399.

NEA report, Trip planning: a market survey (in Dutch: Trip planning: a market survey (in Dutch: Ritplanning een marktverkenning), report NEA 1997, quoted in http://www.clearit.org/pdf/\%27Concurreren.pdf last accessed March 3, 2011

Bai, Y., Hwank, T., Kang, S., Ouyang, Y. (2011). Biofuel refinery location and supply chain planning under traffic congestion. Transportation Research Part B, 45, 162-175. 
Palmer, A. (2007). The development of an integrated routing and carbon dioxide emissions model for goods vehicles. PhD thesis, Cranfield University, School of Management.

Pan, S., Ballot, E., \& Fontane, F. (2010). The reduction of greenhouse gas emissions from freight transport by pooling supply chains. International Journal of Production Economics, "in Press".

Piecyk, M., \& McKinnon, A., (2010). Forecasting the carbon footprint of road freight transport in 2020, International Journal of Production Economics, 128, 31-42

Psaraftis, H.N., Kontovas, C.A., \& Kakalis, N.M.P. (2009). Speed reduction as an emissions reduction measure for fast ships, Proceedings of the 10th International Conference on Fast Sea Transportation FAST 2009, Athens. Retrieved Feb 25, 2011 from http://www.martrans.org/documents/2009/air/FAST\%202009-Psaraftis\%20Kontovas.pdf

Palanivelu, P., Dhawan, M. (2011). Green Logistics. White Paper Tata Consulting Systems. Retrieved March 3, 2010, from http://www.tcs.com/resources/white_papers/Pages/Green_Logistics.aspx.

Quariguasi, F.N J., Walther, G., Bloemhof, J., van Nunen, J., \& Spengler, T., (2009). A methodology for assessing eco-efficiency in logistic networks, European Journal of Operational Research, 193, 647-914.

Quariguasi, J.F.N., Walther, G., Bloemhof-Ruwaard, J.M., van Nunen, J.A.E.E., \& Spengler, T. (2010). From closed loop to sustainable supply chains: the WEEE case. International Journal of Production Research, 48, 4463-4481.

Ramudhin, A., \& Chaabane, A. (2010). Carbon market sensitive sustainable supply chain network design. International Journal of Management Science and Engineering Management, 5, 30-38.

Ubeda, S., Arcelus, F.J., \& Faulin J. (2011). Green logistics at Eroski: A case study. International Journal on Production Economics, "in Press".

Helias, A., \& de Haes, U. (2006). Life-cycle assessment and the use of broad indicators. Journal of Industrial Ecology, 10, 5-7. doi:10.1162/jiec.2006.10.3.5.

Sarkis, J., Zhu, Q., Lai, K. h. (2011). An organizational theoretic review of green supply chain management literature. International Journal of Production Economics, 130, 1-15.

Sheu, J.B., Chou, Y.H., Hu, C.C. (2005). An integrated logistics operational model for green-supply chain management. Transportation Research Part E, 41, 287-313.

Sbihi, A., \& Eglese, R.W. (2010). Combinatorial optimization and Green Logistics. Annals of Operational Research, 175, 159-175. 
Srivastava, S. K. (2007). Green supply-chain management: A state-of-the-art literature review. International Journal of Management Reviews, 9, 53-80.

Sundarakani, B., de Souza, R., Goh, M., Wagner, S.M., \& Manikandan, S. (2010). Modeling carbon footprints across the supply chain. International Journal of Production Economics, 128, 43-50.

Stern, N. (2006). The Stern Review: The Economics of Climate Change, HM Treasury, London. Available from http://siteresources.worldbank.org/INTINDONESIA/Resources/2262711170911056314/3428109-1174614780539/SternReviewEng.pdf.

Vachon, S., \& Klassen, R.D. (2006). Extending green practices across the supply chain - The impact of upstream and downstream integration. International Journal of Operations \& Production Management, 26, 795-821.

Wang, F., Lai, X., Shi, N. (2011). A multi-objective optimization for green supply chain network design. Decision Support Systems, "in Press".

\section{Web References}

CleanAirlnitiative (2011). Air pollution and greenhouse gas emissions from ocean-going ships. Retrieved January 10, 2010, from http://cleanairinitiative.org/portal/node/1864

EEA (2011). EEA Greenhouse Gas Data (2008). Retrieved February 12, 2011, from http://dataservice.eea.europa.eu/PivotApp/pivot.aspx?pivotid=475.

Green Logistics, (2010). Research into the sustainability of logistics systems and supply chains. Retrived August 16, 2011, from http://greenlogistics.org/

lakovou, E., Vlachos, D., Chatzipanagioti, M., Mallidis, I., (2010). A comprehensive Optimization Framework for Sustainable Supply Chain Networks. Retrieved February 26, 2011, from http://im.meng.auth.gr/lascm/data\%20files/pdf/Chatzipanagioti/ICLST_2010.pdf

SCGreen-Global certification program in the supply chain. from http://www.scexecutive.com/index.php?option=com_content\&view=article\&id=1392\&ltemid=545, last accessed March 3, 2011.

TNT (2011). TNT Express services and solutions. Retrieved March 4, 2011 from http://group.tnt.com/Images/20090618_express_services_and_solutions_2009_tcm177-448930.pdf. 